\title{
ARTICLE
}

\section{Scientific Progress and Collective Attitudes}

\author{
Keith Raymond Harris \\ University of Iowa, Philosophy Department, Iowa City, IA, USA \\ Email: keithraymondharris@gmail.com
}

(Received 29 May 2020; revised 20 January 2021; accepted 29 January 2021)

\begin{abstract}
Psychological-epistemic accounts take scientific progress to consist in the development of some psychological-epistemic attitude. Disagreements over what the relevant attitude is true belief, knowledge, or understanding - divide proponents of the semantic, epistemic, and noetic accounts of scientific progress, respectively. Proponents of all such accounts face a common challenge. On the face of it, only individuals have psychological attitudes. However, as I argue in what follows, increases in individual true belief, knowledge, and understanding are neither necessary nor sufficient for scientific progress. Rather than being fatal to the semantic, epistemic, and noetic accounts, this objection shows that these accounts are most plausible when they take the psychological states relevant to scientific progress to be states of communities, rather than individuals. I draw on recent work in social epistemology to develop two ways in which communities can be the bearers of irreducible psychological-epistemic states. Each way yields a strategy by which proponents of one of the psychological-epistemic accounts might attempt to account for the social dimensions of scientific progress. While I present serious reasons for concern about the first strategy, I argue that the second strategy, at least, offers a promising path forward for a psychological-epistemic account of scientific progress.
\end{abstract}

Keywords: Collective attitudes; group belief; group knowledge; scientific progress; social epistemology

\section{Introduction}

Several prominent accounts of scientific progress take such progress to consist in the development of some psychological-epistemic attitude. Disagreements over what the relevant attitude is - true belief, knowledge, or understanding - divide proponents of the semantic, epistemic, and noetic accounts of scientific progress, respectively. These accounts face a common challenge. On the face of it, only individuals have psychological attitudes. However, as I argue in what follows, increases in individual true belief, knowledge, and understanding are neither necessary nor sufficient for scientific progress. Consequently, the semantic, epistemic, and noetic accounts are, it seems, inadequate accounts of scientific progress.

This objection is not by itself fatal to the semantic, epistemic, and noetic accounts, but illustrates that, even if scientific progress consists in the development of some psychological-epistemic attitude, it does not consist in the development of that attitude by individuals. The semantic, epistemic, and noetic accounts are most plausible when they take the psychological states relevant to scientific progress to be states of communities, rather than individuals, or so I argue.

(C) The Author(s), 2021. Published by Cambridge University Press. This is an Open Access article, distributed under the terms of the Creative Commons Attribution licence (http://creativecommons.org/licenses/by/4.0/), which permits unrestricted re-use, distribution, and reproduction in any medium, provided the original work is properly cited. 
One might think that, if the individualist variants of the semantic, epistemic, and noetic accounts are unsuccessful, then no version of these accounts can succeed. This pessimistic conclusion will likely be attractive to many readers due to the widely held view that individuals, and only individuals, are the subjects of psychological states. However, in the second half of this paper, I draw on recent work in social epistemology to develop two strategies by which proponents of one of the psychological-epistemic accounts might attempt to account for the social dimensions of scientific progress. While I present serious reasons for concern about the first strategy, I argue that the second strategy, at least, offers a promising path forward for a psychological-epistemic account of scientific progress. In the final substantive section of this paper, I address two objections to the collective accounts of scientific progress defended here. The first objection alleges that, in light of a recent proposal by Ross (2020) according to which the progress of intellectual communities is due to epistemic improvements of the communities themselves, including the formation of various interrogative attitudes associated with intermediate stages of inquiry, the collective approaches defended here are too restrictive. The second proposal alleges that the ascription of epistemic attitudes not possessed by individual group members to groups themselves is implausible. I argue that neither objection threatens the collective accounts of scientific progress defended here.

\section{Psychological-epistemic accounts of scientific progress}

Let us begin by drawing a distinction between two competing groups of accounts of scientific progress. One group takes scientific progress to consist in the formation of psychological-epistemic attitudes, including true belief, knowledge, and understanding. Call these psychological-epistemic (PE) accounts of scientific progress. The non-psychological-epistemic (Non-PE) accounts do not take scientific progress to consist in the formation of psychological-epistemic attitudes. In this section, I review the most prominent accounts of scientific progress now on offer, sorting each of these into either the PE or Non-PE category. As we will see, some accounts resist straightforward classification. Ultimately, our focus will be on PE accounts of scientific progress.

Before beginning our survey, it is worth recognizing that science might progress, in the relevant sense, in multiple ways (Rowbottom 2015; Niiniluoto 2019). While the accounts discussed in this section mostly take scientific progress to consist either in the formation of some particular psychological-epistemic state, or some increased capacity, one might alternatively take satisfaction of a disjunction of some of the condition(s) discussed here, or some further conditions, to be sufficient. The apparent problem I ultimately raise for $\mathrm{PE}$ accounts of scientific progress will apply to any account that gives place to the formation of psychological-epistemic attitudes, whether this is treated as necessary or merely sufficient for scientific progress.

According to a first account, science aims to get at the truth and science progresses just when this aim is achieved. This semantic account of scientific progress is typically ascribed to Popper $(1963,1972)$ and has been developed more recently by Niiniluoto (1984, 1987, 2014, 2017). Because it is widely recognized that the history of science, at least until recently, is a history of strictly speaking false theories being replaced by further false theories, the semantic account is most plausible when understood as the thesis that scientific progress consists in the approximation, rather than the attainment, of truth.

The apparent simplicity of the semantic account disguises a lack of specificity that is reflected in discussions by its proponents and critics. In his defense of the semantic account, Popper denies that scientific progress requires novel true beliefs by members 
of the scientific community (1972). Instead, scientific progress for Popper consists in the development of the 'third world' of objective knowledge. ${ }^{1}$ This third world is populated by the contents of journals, books, and libraries. These contents include entities such as theoretical systems and arguments, but also states of debates (1972: 107). Crucially, Popper maintains that while the third world of objective knowledge is constructed by humans, the contents of that world need not be matched by knowledge at the individual level (1972: 109). Whereas Popper's semantic account centers on the attainment of truth, independent of belief, Alexander Bird's influential critiques of the semantic account are directed at the thesis, endorsed by Niiniluoto, that scientific progress is realized through the formation of new true scientific beliefs (Bird 2007). The distinct interpretations to which the semantic account is subject help illustrate the distinction between the PE and Non-PE accounts of scientific progress at the center of this essay. On Popper's version of the semantic account, it is a Non-PE account. Bird, however, critiques a PE version of the semantic account. The semantic account thus straddles the distinction between PE and Non-PE accounts of scientific progress. Because our focus is on the plausibility of PE accounts, I focus here on the version of the semantic account critiqued by Bird. Subsequent references to the semantic account should be understood as concerning that version of the account specifically.

Bird's $(2007,2008)$ preferred account of scientific progress takes such progress to consist in increases in scientific knowledge, rather than mere true belief. Because knowledge implies true belief, but not vice versa, this epistemic account locates scientific progress in a subset of the episodes that the semantic account treats as progressive. Bird motivates the epistemic account by pointing to cases in which a new true scientific belief is formed but the belief either lacks justification or is tainted by epistemic luck, and thus fails to constitute knowledge. ${ }^{2}$ Such episodes fail to constitute scientific progress, or so Bird contends. Consequently, the semantic account is an excessively permissive account of scientific progress.

Here it is worth making two points related to the semantic and epistemic accounts. First, there is logical space for an account of scientific progress more demanding than the semantic account but less demanding than the epistemic account. Such an account might take scientific progress to consist in the formation of justified true beliefs, regardless of whether such beliefs constitute knowledge. I raise this point to better highlight the range of views that will ultimately be subject to the prima facie challenge developed below. Second, the epistemic account, like the relevant form of the semantic account, is subject to this challenge because it is a PE account of scientific progress.

Dellsén $(2016,2018 a, 2018 b)$ proposes the noetic account as an alternative to both the semantic and epistemic accounts. On the noetic account, scientific progress is achieved through increases in understanding. This description of the noetic account leaves its details open, as there is considerable disagreement among philosophers as to the nature of understanding. Much of this disagreement centers on whether

\footnotetext{
${ }^{1}$ That Popper uses the term 'knowledge' to describe the contents of his third world should not lead one to suppose that Popper's account is a version of the epistemic account. For one thing, Popper takes objective knowledge to be an entirely distinct phenomenon to that with which epistemologists have traditionally been occupied (1972: 108).

${ }^{2}$ In a recent paper, Bird (2019) argues that the constitutive aim of science is knowledge. This view, combined with the assumption that an institution progresses just when it advances one of its constitutive aims, might be thought to lend additional support for the epistemic account. Indeed, Bird elsewhere suggests such a line of argument (2007: 111). Bird instead uses the epistemic account, combined with this assumption, to argue for knowledge as the constitutive aim of science (2019: 175-6). Because I am not concerned here with favoring any particular PE account of scientific progress, I will not consider either line of argument at length here.
} 
understanding is a species of knowledge. ${ }^{3}$ Dellsén (2017) denies that understanding requires belief or justification and, a fortiori, that understanding is or requires knowledge. Dellsén takes understanding to require at least a partial grasp of 'how to correctly explain and predict aspects of a given target' (2016: 74) and follows Grimm in identifying grasping as 'an ability not just to register how things are, but also an ability to anticipate how certain elements of the system would behave, were other elements different' (Grimm 2011a: 89). Most importantly for present purposes, Dellsén identifies this ability as a psychological property (2016: 75). Elsewhere, against the view that understanding requires belief, Dellsén suggests that grasping can be achieved through acceptance, rather than belief (2017: 248). Dellsén is again explicit that acceptance is a psychological state (2017: fn. 16). So understood, the noetic account is a PE account.

I turn now briefly to two accounts of scientific progress that are naturally understood as Non-PE accounts. On the problem-solving account, typically associated with antirealism in philosophy of science, scientific progress occurs to the extent that later theories solve more problems than their predecessors. The problem-solving account has prominent defenders, including Kuhn $(1970,1977)$ and Laudan $(1977,1981)$. On Laudan's approach, the problems that theories confront may either be internal to theory or may concern unexplained apparent phenomena (1981: 146). To the extent that later theories solve more problems than earlier theories - leaving fewer apparent phenomena unexplained and enjoying a greater degree of internal consistency and compatibility with the theory and practice of science more generally - science progresses.

On the face of it, the problem-solving account is a Non-PE account. Progress is made, or not, from one body of scientific theories to another, and the account makes no overt reference to psychological-epistemic attitudes toward theories. Still, it would be premature to conclude that the problem-solving account gives no place to psychological-epistemic attitudes. Consider how Laudan summarizes the central claims of the account:

The aim of science is to secure theories with a high problem-solving effectiveness.

From this perspective, science progresses just in case successive theories solve more problems than their predecessors. (Laudan 1981: 145, emphasis in original)

The problem-solving account is a Non-PE account only if the notion of securing theories can be understood without reference to psychological-epistemic attitudes. Some proponents of the problem-solving account would likely take the formulation of problems and the capacity to solve problems to involve some sort of psychologicalepistemic relation. ${ }^{4}$ However, it is at least in principle possible that the problem-solving account might be specified to require the mere formulation or representation of a theory with relatively great problem-solving power, without requiring that any psychologicalepistemic attitude be taken toward that theory. Given the latter possibility, the account at least potentially avoids the line of objection to be raised below.

To conclude this section, consider a final account of scientific progress drawn from work by Mizrahi (2013) and Douglas (2014). Mizrahi points to case studies from the history of science to motivate a revision to the epistemic account on which scientific progress can be realized not only through increases in propositional knowledge, but also through increases in knowledge-how. Similarly, Douglas suggests an account of scientific progress on which scientific progress consists in "the increased capacity to

\footnotetext{
${ }^{3}$ For the claim that understanding is a species of knowledge, see, for some examples, Lipton (2004) and Grimm (2006). For the denial of this claim, see Zagzebski (2001) and Kvanvig (2003).

${ }^{4}$ Thanks to an anonymous reviewer for raising this point.
} 
predict, control, manipulate, and intervene in various contexts" (2014: 62). What is common to the accounts offered by Mizrahi and Douglas is the suggestion that scientific progress consists not strictly in increases in true belief or knowledge, but in increased knowledge-how. Call any account on which increases in scientific knowledgehow ${ }^{5}$ are constitutive of scientific progress a pragmatic account. ${ }^{6}$ Pragmatic accounts thus include all accounts that take increases in scientific knowledge-how to be sufficient for scientific progress, regardless of whether these accounts take such increases to also be necessary for scientific progress. Strictly speaking, then, some pragmatic accounts may straightforwardly face the same challenges as PE accounts, insofar as they may explicitly allow that the development of PE attitudes, in addition to the development of scientific knowledge-how, is constitutive of scientific progress ${ }^{7}$. However, because there might in principle be a pragmatic account that takes scientific progress to consist solely in the development of scientific knowledge-how, it is worth asking whether such an account would be a PE account.

The extent to which the pragmatic account differs from the epistemic account of scientific progress depends on whether knowledge-how is a form of propositional knowledge, an issue that has been hotly disputed in the past two decades. Stanley and Williamson (2001) provide a prominent defense of the claim that knowledge-how is a species of propositional knowledge. Even on Stanley and Williamson's propositional intellectualist account, knowledge-how is understood as a special kind of propositional knowledge propositional knowledge under a practical mode of presentation. Thus, even if propositional intellectualism is true, an account of scientific progress on which knowledge-how is constitutive of scientific progress would depart from the epistemic account.

Some alternative accounts of knowledge-how treat knowledge-how as an ability that can be had independently of propositional knowledge (Hawley 2003; Noë 2005). On these alternative accounts, coupled with the pragmatic account, scientific progress can be achieved through increases in abilities, without requiring additional propositional knowledge. For present purposes, the relevant point is that pragmatic accounts may or may not be PE accounts, depending on how knowledge-how is understood.

In this section, we have reviewed six accounts of scientific progress, including two distinct versions of the semantic account. Three of these accounts - the epistemic account, the noetic account, and one version of the semantic account - are straightforwardly PE accounts of scientific progress. We have also seen that at least some versions of the problem-solving account and pragmatic accounts of scientific progress may be understood as taking scientific progress to consist in the formation of psychological-epistemic attitudes. I now develop a prima facie challenge to every account of scientific progress that appeals to such attitudes. Because only the semantic, epistemic, and noetic accounts explicitly appeal to such attitudes, I focus the objection, as well as the discussion of possible defenses against the objection, on these accounts.

\section{Scientific progress, collectives, and communities}

In this section and the next I develop a challenge against PE accounts of scientific progress. The essence of the challenge is that, on the face of things, there is no suitable subject of the attitudes that PE take to be constitutive of scientific progress. This is because,

\footnotetext{
${ }^{5}$ Because the issue of what counts as scientific knowledge-how is tangential to the focus of the present paper, I will not attempt to provide an account of such knowledge-how here. Instead, I take for granted that at least some knowledge-how is plainly scientific know-how.

${ }^{6}$ For an earlier pragmatic account that emphasizes the role of instruments in increasing scientific knowledge-how see Baird and Faust (1990).

${ }^{7}$ Thanks to an anonymous reviewer for pressing me on this point.
} 
at least according to philosophical orthodoxy, the only potential subjects of psychological attitudes are biological individuals, and the formation of individual true beliefs, knowledge, and understanding are neither generally necessary nor generally sufficient for scientific progress. Ultimately, I argue that the failure of individualist versions of the PE accounts of scientific progress suggests that, if any PE account succeeds, it will be one on which scientific progress is realized through epistemic improvements to the psychological states of communities, rather than individuals. This approach is not entirely novel, and a similar proposal has been defended by Ross. I consider Ross's proposal at greater length in section 6 . I begin to defend the collective approach by distinguishing two questions related to scientific progress. ${ }^{8}$ One question concerns the subject or subjects of scientific progress - that is, the entity that undergoes scientific progress. A second question concerns what entity or entities' properties are constitutive of scientific progress. While the answer to the former question does not settle the latter, the answer will, I suggest, constrain plausible answers to the latter question. I provide a preliminary answer to the former question in this section, and begin to address the second question in section 3 .

To start, we may ask why we should regard scientific progress as being undergone by a particular entity or entities at all. Could scientific progress occur, without being undergone by any particular entity? This seems unlikely. The concept of progress in at least some areas - moral, technological, intellectual, and so on - typically presupposes a subject. In some cases, this subject is an individual. In other cases, the subject is some collective or institution. In the absence of clear examples of progress without a subject, it is reasonable to suppose that scientific progress, like other forms of progress, is undergone by some entity. Moreover, even if we could understand some depersonalized sense of scientific progress, this is not the sense of progress with which philosophers working on this issue are typically concerned. The point is typically not made explicit, but is apparent in, for instance, Rowbottom's (2010) thought experiments involving different levels of scientific progress achieved on different planets. Implicit in such thought experiments is the assumption that scientific progress is localized. A depersonalized sense of scientific progress cannot capture this plausible assumption.

A second possibility is that scientific progress is undergone by entities that are constructed by, but entirely distinct from human individuals. This possibility is suggested by the following analogy from Popper. Popper thinks of science as being constructed through human activity, but with an existence independent of that of its human creators, in the same way that a spider's web or a bird's nest exists independently of its animal creator (1972: 112). Perhaps a better analogy is a beaver dam, which might grow and develop over generations of animals. We might think of a beaver dam as undergoing progress to the extent that it grows over time. Similarly, we might think of science as progressing to the extent that some product, created by but existing independently of human individuals, expands. For example, we might think that science progresses through the accumulation of scientific facts, as represented in journal articles, books,

\footnotetext{
${ }^{8}$ Ross distinguishes between a question concerning the explanandum of accounts of progress and a question concerning the subjects that should be focused upon in accounts of progress (2020: 3-4). The second question I address, and Ross's second question, are similar except for my narrow focus on scientific progress. Our first questions differ in an additional important way, however. Ross argues briefly that the explanandum of accounts of progress is "the success or otherwise of some multi-agent endeavour" (2020: 3). This answer does not yet answer the question of what entity undergoes progress, however. As we will see in what follows, it is possible that scientific progress is a collective endeavor within which progress is undergone by some product produced by, but entirely distinct from, human individuals.
} 
and other products produced by, but existing independent of, human individuals. The entity that undergoes scientific progress, then, is this body of products.

In the present context, the preceding suggestion faces significant objections. First, the suggested account is at most a PE account of scientific progress in name only. While Popper thinks that the accumulation of objective knowledge does in fact proceed in this way, it is clear that objective knowledge is not a recognizable variant of what philosophers typically think of as knowledge. Knowledge, on the standard view, is or at least requires a mental state and it is plain that objective knowledge neither is nor requires a mental state. The suggested account is thus, despite superficial appearances, not a version of the epistemic account. Nor is it any other kind of PE account. To the extent that one finds the suggested account plausible, one might conclude that the search for a plausible PE account is simply a mistake and perhaps that some version of Popper's non-PE semantic account is preferable. My principal aim here is to present a challenge for existing PE accounts and to propose an alternative, and so I will not offer a thorough assessment of this response. However, there is reason to deny that the entity that undergoes scientific progress is some mass of journal articles, books, and so on. After all, the suggestion that the entity that undergoes scientific progress is some entity that is the product of human agency, but exists entirely independent of human persons, runs counter to the plausible constraint that scientific progress is undergone, in one way or another, by humans. Let us consider some alternative accounts that respect this constraint.

Supposing scientific progress is a property of some human entity, a first possibility is that scientific progress is progress of individuals. However, this view cannot account for the widely accepted claim that scientific progress has occurred throughout history, and through generations of scientists. While individuals make scientific progress, they do not themselves undergo scientific progress. In other words, even if one thinks individual actions and attitudes produce scientific progress, it seems that individuals are not the subjects of scientific progress. If scientific progress is undergone by some entity or entities, but not by individuals, the only initially plausible remaining option is that scientific progress is undergone by collectives. Notably, the view that scientific progress is undergone by collectives of some sort could capture the intuitive assumption underlying Rowbottom's thought experiments.

Even supposing that scientific progress is undergone by collectives, there remains considerable uncertainty regarding what sorts of collectives undergo scientific progress. Consider some possible candidates. This list includes research teams, communities of scientists working in specific subfields, the scientific community more generally, geopolitical communities, and humanity itself. Which of these entities can undergo scientific progress? We need not assume from the outset that there is just one answer to the question. In fact, scientific progress can felicitously be ascribed to many distinct types of collective entities. A single discovery may, for instance, be described as progress undergone by a team of particle physicists, the particle physics community, the scientific community, and humanity itself. However, even if scientific progress can felicitously be ascribed to all such collective entities, it may nonetheless be that there is one primary subject of scientific progress and a range of entities that make scientific progress in some derivative sense. In what follows, I aim to narrow down the field of entities that can plausibly be taken as the primary subjects of scientific progress.

First, the view that research teams are the primary subjects of scientific progress cannot account for the progress of science throughout history and so, like the view that individuals are the primary subjects of scientific progress, should be set aside. Second, while progress is often ascribed to subfields of science, there is reason to think that these subfields - which I am supposing are constituted at a time by the 
evolving body of individuals that make them up at that time - are not the primary subjects of scientific progress. One consideration in support of this conclusion is that the emergence of new scientific subfields is itself plausibly constitutive of scientific progress. ${ }^{9}$ A second supporting consideration is that, given the interdependency of subfields, events cannot safely be identified as progressive for some subfield(s) of science, but not others. The import of a discovery may not be realized until long after that discovery is made. Consequently, a discovery may be recognized as progressive even if it is not recognized which fields the discovery promises to progress. This suggests that scientific progress is, at least in the first instance, a property of some collective other than scientific subfields. From our list of candidates for the bearers of scientific progress, this leaves only the scientific community, geopolitical communities, and humanity itself. This argument by elimination is limited by both the non-exhaustiveness of our initial list and the inconclusive nature of certain of the arguments presented against items on that list. Still, we have at least some reason to focus on this narrowed list of candidates.

Determining which, if any, of these candidates is the primary subject of scientific progress is difficult, as competing considerations pull in different directions. The view that geopolitical communities make scientific progress is motivated by examples like the nuclear arms race following the Second World War. It seems plausible to say, in this case, that scientific progress was relativized to distinct geopolitical communities. However, this view, like the one on which individuals or research teams undergo scientific progress, has difficulty accounting for the progress of science throughout history. The alternative views, on which scientific progress is undergone either by the scientific community or by humanity itself, have difficulty accounting for the apparent possibility that progress might occur within one community even as it stalls elsewhere, but can account for the progress of science throughout history. One option open to those who think either the scientific community or humanity itself is the primary subject of scientific progress is to argue that, while other entities make scientific progress only the scientific community or humanity itself undergoes scientific progress. That is, the discoveries attributable to individuals, research teams, scientific subfields, or geopolitical communities are constitutive of scientific progress, but this progress is itself a property of the broader communities in which they are embedded.

Let us take stock. I have in this section argued that scientific progress is a property of some sort(s) of communities. Whether scientific progress is undergone by geopolitical communities, the scientific community, or humanity itself is an interesting question in its own right, but one that I will not attempt to settle here. For present purposes, what matters is that scientific progress is not undergone by entities entirely distinct from human individuals, human individuals themselves, or by research teams. While this conclusion does not settle the further question of what entities' properties are constitutive of scientific progress, ${ }^{10}$ it does constrain plausible answers to this further question. I now address this further question directly.

\footnotetext{
${ }^{9}$ If the emergence of new scientific subfields is constitutive of scientific progress, then each of the PE accounts provides, at most, part of the story of what constitutes scientific progress. It is in part for this reason that, in section 1, I emphasized that the challenge developed in section 2 afflicts any account of scientific progress that takes the development of psychological-epistemic attitudes to be constitutive of scientific progress, whether or not such developments are required for scientific progress.

${ }^{10}$ For example, although Bird recognizes communities as the entities that undergo scientific progress (2007: 94), his account nonetheless emphasizes the epistemic states of individuals. More generally, it could in principle be the case that, while collectives undergo scientific progress, such progress occurs through changes in the attitudes of individuals.
} 


\section{Scientific progress and individual attitudes}

Supposing that scientific progress is a property of communities, how is such progress achieved? According to the PE accounts, scientific progress consists in the development of psychological-epistemic attitudes - true belief, knowledge, or understanding. I now consider several proposals for making this suggestion concrete. Each proposal considered in this section is individualist, in that it takes scientific progress to consist in the development of individual psychological-epistemic states.

According to a first proposal, scientific progress is achieved just when any individual attains a new true belief, knowledge, or understanding of some scientific proposition or phenomenon. This first proposal yields an excessively liberal account of how easily scientific progress is achieved, however. On this first proposal, the education of students, insofar as it improves the epistemic states of individual students, is constitutive of scientific progress. However, while science education undoubtedly promotes scientific progress, such education is not constitutive of scientific progress. ${ }^{11}$ When we tout the scientific progress that has been made over the centuries, we are not in the first instance interested in the increasingly widespread availability of scientific education - even though these achievements are undoubtedly causally interconnected.

Taking on board what is learned from the failure of the first proposal, one might suggest instead that scientific progress is achieved just when some individual comes to stand in the relevant psychological-epistemic relation toward a new target scientific proposition or phenomenon. Call an instance of true scientific belief, scientific knowledge, or scientific understanding novel if it is the first instance of someone standing in that relation to a given target. On the present proposal, only novel psychological-epistemic attitudes constitute scientific progress. This proposal rightly captures that the education of students is not constitutive of scientific progress. More generally, this proposal captures that scientific progress is plausibly about expanding the frontiers of science, rather than disseminating the existing fruits of science. Nonetheless, the proposal seems to set standards for scientific progress that are at once too lax and too restrictive.

Consider first how the proposal makes the standards for scientific progress too lax. Suppose that, in her home lab in a remote corner of the world, an isolated scientist makes a novel observation and formulates a new true theory that captures the observed phenomenon. She thereby develops a novel true belief, novel knowledge, and novel understanding. Even if such a case were to occur - something unlikely given the collaborative nature of modern science - scientific progress would intuitively not thereby occur. Novel epistemic improvements on the part of some individual are thus not sufficient for scientific progress. I consider an objection to this brief argument shortly. Before doing so, I argue that novel epistemic improvements on the part of individuals are not generally necessary for scientific progress.

Let us suppose that there is an omniscient, or near-omniscient being. As human beings make novel scientific discoveries, improving their own epistemic situations in the process, none of what is uncovered is new, for this being is already at least as well situated epistemically as any human individual. Consequently, if scientific progress requires novelty in the sense described thus far, no scientific progress is made in the scenario described. It is, I submit, implausible that a world with an omniscient or

\footnotetext{
${ }^{11}$ Ross argues in a similar vein that one scientist informing colleagues of a scientific fact does not amount to scientific progress (2020: 6). Bird (2010:30) makes the related point that discoveries kept under wraps by individuals do not contribute to collective scientific knowledge. It should be noted, though, that while Bird endorses the epistemic account and endorses the existence of collective scientific knowledge, he is not explicitly committed to the collective epistemic account I describe below.
} 
near-omniscient being is a world in which scientific progress cannot be made. Even if one takes judgments concerning cases involving such strange beings to lack authority, the basic point can be made by considering a structurally similar case. It is likewise implausible that whether a community can undergo scientific progress depends on whether there exists some distant community, perhaps in a remote corner of the universe, at a further stage of scientific development. In summary, because the proposal allows that individual epistemic improvements are constitutive of scientific progress, it makes such progress implausibly easy to achieve. However, because the proposal also requires novelty, it simultaneously makes scientific progress implausibly difficult to achieve.

It might be thought that these objections fail to undermine the second proposal and that they instead underscore the point made in section 2. There, I argued that scientific progress is a property of communities. Taking on board this insight, one might suggest that the best version of the second proposal is one on which a community makes progress just when one of its members makes an epistemic achievement that is novel within the community. This response arguably deals with both of the objections raised against the second proposal. Scientific progress is possible within a community, despite the existence of an omniscient being, so long as this being is not a member of the community. Moreover, the lone scientist's discoveries fail to constitute scientific progress because this scientist does not belong to a community.

That the second proposal becomes more defensible when the lessons of section 2 are taken on board underscores the importance of recognizing that scientific progress is a property of communities. Still, the second proposal places implausibly liberal conditions on scientific progress. To see this, consider a case involving a scientist that is undoubtedly a member of a community. Just what such membership consists in is a substantive question, and one I will not attempt to settle here. However, we may build the case so that the scientist is, as uncontroversially as possible, a member of a community. This may involve her publishing articles in scientific journals, managing a lab, instructing students, and so on. Suppose that this scientist is deeply invested in the truth of a particular theory but, in the course of her work, uncovers evidence that strongly undermines that theory, and supports a rival theory. In the process, she develops new true beliefs, new knowledge, and new understanding related to some target phenomenon. However, because she has pragmatic reason to do so, she suppresses her own discovery, never sharing it with other members of her community. ${ }^{12}$ Despite the epistemic improvements the individual scientist undergoes, it seems that her community does not thereby undergo scientific progress. Thus, the achievement of novel epistemic states on the part of some individual are not sufficient for scientific progress, even when that individual is a community member.

The failure of this proposal suggests a third alternative. One might think that, while novel discoveries on the part of some individual are not sufficient for scientific progress, even when that individual is a member of a community, scientific progress is nonetheless ultimately a matter of the novel psychological-epistemic attitudes of individuals. What is required is that these attitudes be widespread, or so one might think. To get this proposal off the ground, we would first require a looser understanding of novelty one permitting a psychological-epistemic attitude to count as novel so long as the epistemic state achieved is not already widespread within the community. On this new proposal, science makes progress just when some significant portion of individuals

\footnotetext{
${ }^{12}$ Ross (2020: 7) presents a similar case involving researchers who perish along with the physical records of their findings before these findings are brought to the attention of their community. Both cases illustrate that epistemic improvements to members of a community are not by themselves constitutive of progress.
} 
form the relevant novel psychological-epistemic attitude. One difficulty with this proposal is that it would again allow for the education of students to be constitutive of scientific progress. The objection is perhaps not fatal in this case, as the proposal need not allow that the education of students is always or even typically constitutive of scientific progress. Ordinarily, students will only be taught in such a way as to develop true beliefs, knowledge, or understanding that is already held by many members of the community, so the current proposal is consistent with affirming that the education of students is typically not constitutive of scientific progress.

However, there are further difficulties with the present proposal, having to do with the extent to which novel epistemic states - true belief, knowledge, or understanding must be widespread for scientific progress to occur. First, it seems that there is no apparent non-arbitrary threshold for individual epistemic properties that can plausibly be taken to be required for scientific progress to occur. ${ }^{13}$ This first difficulty arguably constitutes more of a puzzle than a problem, as one might argue that there is, despite appearances, a non-arbitrary threshold. A more straightforward problem is that, in some cases at least, it seems that scientific progress can be made with few individuals coming to develop new true beliefs, knowledge, or understanding. This is merely to assert that discoveries in obscure scientific subfields constitute genuine scientific progress, a point also made by Ross (2020: 6). Given that some genuinely progressive episodes in science involve epistemic improvements on the part of only a small number of individuals, the significance of widespread psychological-epistemic attitudes to scientific progress is dubious.

Consider a final objection to all the proposals advanced in this section. This objection is best introduced by considering the sorts of cases in which scientific progress may be lost. Suppose that every material trace of some scientific finding - including books, journal articles, and the like - is destroyed. Plausibly, such an event might reverse earlier scientific progress, even if no individual is harmed in the event. ${ }^{14}$ While an event of this sort is difficult to imagine in the present era, where technology typically ensures that stores of important information are redundant many times over, events of this sort have plausibly occurred in the form of, for instance, the destruction of ancient libraries. Similarly, it seems plausible that increases in the amount of information now stored in books and journal articles is constitutive of scientific progress, ${ }^{15}$ even in cases where no living individual is aware of that information (cf. Bird 2010: 35). If so, then scientific progress depends on more than the psychological-epistemic attitudes of individuals.

The upshot of this section is that the progress of science does not consist in the formation of psychological-epistemic attitudes at the individual level, even when attitudes are both novel and widespread. In short, no individualist PE account succeeds. This result casts significant doubt on the semantic, epistemic, and noetic accounts of scientific progress, insofar as these accounts take scientific progress to consist in the formation of psychological-epistemic attitudes. However, as I now argue, the failure of

\footnotetext{
${ }^{13}$ The problem here is analogous to the threshold problem in traditional epistemology, which concerns the degree of justification required for a true belief to count as knowledge (Hetherington 2001, 2006; Bonjour \& Sosa 2003; Grimm 2011b, 2015; Hannon 2017, 2020). A related problem arises for those who take group-level justified belief to require that some portion of group members possess the corresponding justified belief. For some responses to this problem, see Goldman (2014) and Lackey (2016: fn. 40).

${ }^{14}$ Popper (1972: 108) makes a similar point about the possible loss of objective knowledge through destruction of libraries.

${ }^{15}$ It is worth emphasizing, given our discussion in section 2, that it is consistent with the point that material stores of information do not themselves undergo scientific progress that increases in the amount of information included in these stores is constitutive of scientific progress.
} 
individualist versions of the PE accounts is not, by itself, fatal to the PE accounts of scientific progress.

\section{Scientific progress and social justification}

Supposing it has been established that scientific progress does not consist in the formation of psychological-epistemic attitudes by individuals, the only remaining option for the semantic, epistemic, and noetic accounts is to take a collectivist form. The conclusion reached so far may thus seem to spell doom for the PE accounts of scientific progress. However, recent work in social epistemology suggests that groups of individuals can in some cases form psychological-epistemic attitudes over and above the attitudes of their members. In this section and the next, I consider two strategies by which one or more of the PE accounts discussed in section 1 might be defended by appeal to collective psychological-epistemic attitudes.

We begin with de Ridder's (2014) argument that much scientific knowledge is collective knowledge. As de Ridder observes, the orthodox position among contemporary epistemologists is that the possession of knowledge by an entity requires the satisfaction of four conditions: (i) truth, (ii) belief, (iii) justification, and (iv) an anti-Gettier condition. Because a collective entity may in principle possess knowledge not possessed by any of its members by satisfying any one of these conditions that is not satisfied by any of its members, there are multiple ways in which a collective may in principle possess knowledge not possessed by any of its members. However, as de Ridder observes, it is implausible that such a separation will occur in the case of condition (i), as what is true for a group is plausibly always true for that group's members (2014: 42). Although (iv) might well be satisfied by a group, but not its members, I do not pursue that possibility here. Instead, in this section, I consider de Ridder's suggestion that groups sometimes satisfy (iii) without this condition being satisfied by any group members. Then, in section 5, I consider the possibility that groups might believe propositions not believed by any group members.

De Ridder's argument that much scientific knowledge is collective knowledge appeals to the following principle:

(SJ) A subject S's belief that $p$ has scientific justification only if it is properly based on a properly performed and objectively reliable process of scientific inquiry, the purpose of which was to gather evidence for the truth of $p$, and $S$ understands this

to be so. (2014: 45)

Because SJ expresses a necessary condition on scientific justification, and scientific justification is necessary for scientific knowledge, SJ likewise expresses a necessary condition on scientific knowledge. According to de Ridder, the collective nature of contemporary science has the consequence that, in many purported cases of scientific knowledge, no individual can satisfy SJ. This is due to scientists' mutual epistemic dependence - resulting from both time constraints and specialization - on colleagues and predecessors ${ }^{16}$ (de Ridder 2014: 46-7). Dependency on others may take the form of a reliance on other members of one's research team for theoretical and practical expertise that one lacks, as well as broader reliance on the experimental results of one's more distantly connected colleagues. In each case, dependency is mutual insofar as others simultaneously rely on one's own practical and theoretical expertise and findings.

\footnotetext{
${ }^{16}$ De Ridder explicitly allows that mutual dependence may hold between contemporary scientists and their predecessors (2014: 46). Because I find the mutuality of such dependence somewhat mysterious, I focus in what follows on mutual dependence among contemporary colleagues.
} 
Dependency on others renders individual scientists incapable of fully assessing the reliability of the process by which scientific beliefs are formed and so incapable of individually satisfying SJ, at least in many cases. Thus, even if a collective's beliefs are nothing over and above the aggregated beliefs of that collective's individual members, a collective may possess scientific knowledge not possessed by any of its members (de Ridder 2014: 50). This is important for de Ridder, who takes the notion of irreducible collective belief to be problematic (2014: 42).

Building on de Ridder's conception of collective scientific knowledge, we may formulate a new, collective version of the epistemic account of scientific progress. On this version, scientific progress is made just when new collective scientific knowledge is formed. This version of the epistemic account deals handily with the case of the lone scientist for, in this case, there is no mutual epistemic dependency, and so there is no collective scientific knowledge. But does the resulting account adequately capture the epistemic dimensions of scientific progress? In what follows, I articulate some points of concern.

It is first worth noting that, on the account of scientific knowledge now under consideration, the possessors of scientific knowledge are an array of groups with varying degrees of structure. Scientific knowledge will in some cases be a property of research teams with specific aims and purposes. However, in other cases, scientific knowledge will be a property of loose collections of contemporaries who, without explicit cooperation, benefit from one another's work. On this view, the existence of mutual citation is a rough indicator of the existence of group knowledge - only rough because mutual citation need not always reflect mutual epistemic dependency. I now raise worries for the connection between these forms of knowledge and scientific progress.

First, consider a research team whose members are mutually epistemically dependent and which thus, in the course of the team's work, forms a novel true belief that $p$. Let us suppose that the team's belief satisfies SJ, and thus that the team knows that $p$. A first concern for the account of scientific progress now under consideration is that the events described do not seem to be sufficient for scientific progress. Suppose that the team, like the researcher discussed in section 3, has pragmatic reason to suppress its discovery. In this case, it seems that the team's formation of knowledge that $p$ is not sufficient for scientific progress. This is especially clear if we assume that scientific progress is a property of communities, rather than research teams.

There is a broader concern about this account worth raising here. De Ridder, as I noted, maintains that justification is sometimes irreducibly collective even though belief is at most reducibly collective - that is, he maintains that a collective's belief that $p$ is reducible to its individual members' beliefs that $p$. De Ridder is, however, also committed to a basing condition on knowledge - for $\mathrm{S}$ to know $p, \mathrm{~S}$ must understand S's belief that $p$ to be 'properly based on a properly performed and objectively reliable process of scientific inquiry' (2014: 45). But, in cases of mutual epistemic dependence, no individual satisfies this condition. But, given that no individual satisfies the condition, and the collective's belief is just the aggregate of its individual members' beliefs, it is unclear how the collective can satisfy the basing condition on knowledge. This problem casts doubt on de Ridder's account of collective scientific knowledge in general, and the application of that account to the issue of scientific progress in particular.

The concern just raised against de Ridder's account of collective scientific knowledge has broad implications. It is quite plausible that any adequate account of knowledge will include a basing condition and, as we have seen, the satisfaction of this condition seems to exclude the possibility of collective knowledge based on irreducibly collective justification, without irreducibly collective belief. The lesson is that there is no irreducibly collective knowledge without irreducibly collective belief. In the next section, I develop a 
strategy for defending the PE accounts of scientific progress that appeals to irreducibly collective beliefs and other mental states.

\section{Scientific progress and collective attitudes}

De Ridder's account of collective scientific knowledge is consistent with the denial that there are irreducibly collective mental states. The approach taken in this section departs from the philosophically conservative position that only individuals are the subjects of mental states. First, I develop a strategy for reconciling the semantic and epistemic accounts with the social dimensions of science by defending the possibility of irreducibly collective true belief and knowledge. I then consider whether this strategy can be extended in defense of the noetic account.

Supposing that the defensibility of the PE accounts depends on commitment to irreducibly collective mental states, one might conclude that the PE accounts are best set aside. However, recent work on extended and distributed cognition casts doubt on the widely held presumption that individuals are the only subjects of mental states. The hypothesis of extended cognition, together with the extended mind thesis, are typically taken to support the view that the realization bases of individual's cognitive processes and mental states are not confined within biological barriers (Clark 1997, 2008; Clark and Chalmers 1998; Hurley 2010; Milojevic 2020). However, I have recently argued that the extended mind thesis is most plausible when understood as the claim that biological individuals sometimes form parts of distinct systems that are themselves the subjects of mental states (Harris 2019, 2020). This understanding of the extended mind thesis brings it into closer alignment with the hypothesis of distributed cognition, on which cognitive processes are sometimes distributed across systems of biological and non-biological components (Hutchins 1995; Davies and Michaelian 2016). For present purposes, what matters is that the assumption that biological individuals are the sole bearers of mental states cannot be taken for granted. Thus, the failure of individualist versions of the $\mathrm{PE}$ accounts does not spell doom for those accounts.

In fact, Bird $(2010,2014)$ has recently developed an account of scientific knowledge as social knowing that is motivated in part by work on distributed cognition. ${ }^{17}$ Bird's account of scientific knowledge is intended to capture the sense of knowledge at work in sentences like 'North Korea knows how to build an atomic bomb' (2010: 23) and 'The growth of scientific knowledge has been exponential since the scientific revolution' (2010: 25). Notably, this knowledge is plausibly not held by any single individual, but is instead distributed across several individuals and, perhaps, non-biological stores of information. More generally, Bird maintains that scientific knowledge is not reducible to the knowledge of individuals, but is instead realized in the states of individuals together with material stores of information including books, journal articles, and so on. Here it is worth making a few points of clarification. First, to say that scientific knowledge is distributed across individuals and material stores of information is not to deny that some items of scientific knowledge might be fully realized in the states of particular individuals and material stores of information. ${ }^{18}$ For instance, social knowledge

\footnotetext{
${ }^{17}$ The distributed cognition approach utilized by Bird and taken up here is not the only way to develop accounts of irreducibly collective belief and knowledge. Gilbert's (1987, 1989, 1994, 2000) joint commitment approach represents an important alternative approach to group belief. Because of concerns about whether joint commitment gives rise to genuine beliefs that are properly responsive to epistemic considerations (Wray 2001), I do not consider Gilbert's approach at length here.

${ }^{18}$ Bird sometimes writes as though scientific knowledge is exclusively realized in the states of published or otherwise accessible material stores of information (2010:31). This position is motivated by the case of a hermit scientist whose discoveries, Bird suggests plausibly, do not automatically contribute to scientific
} 
that $p$ could in principle be realized entirely in the states of a single book. What allows the contents of the book to contribute to social knowing is the accessibility of those contents (Bird 2010: 32). Second, while Bird devotes little attention to the question of justification, it is consistent with Bird's approach that there is a justification component to social knowing. Justification, on Bird's approach, is perhaps best understood as deriving from the reliability of the scientific process that issues in content distributed across individuals in non-biological stores of information (2010: 42). Extending Bird's approach, we may say that social beliefs, the realization bases of which are likewise distributed across individuals and material stores of information, ${ }^{19}$ may or may not constitute social knowledge depending on whether or not these beliefs are true and produced by a reliable process.

Rather than scrutinizing Bird's account of social knowing in detail, I instead wish to consider how the account might be brought to bear on the question of scientific progress. The suggestion here is that scientific progress occurs just when scientific social knowledge increases. Call this the collective epistemic account. The present suggestion deals easily with the objections raised against the individualist variants of the epistemic account considered in section 3. The development of scientific knowledge by some isolated individual does not constitute scientific progress, because this individual's knowledge is not accessible in the way required for social knowledge. Moreover, the collective epistemic account explains why scientific progress can be lost without any individual being directly affected, as in the case of the destruction of material stores of information.

We can likewise construct an account on which scientific progress consists in the development of true social beliefs. Call this the collective semantic account. On this account, the production of social beliefs by reliable scientific processes is not strictly required for scientific progress, but will tend to ensure that true rather than false scientific beliefs are formed, and thus will promote scientific progress. Like the collective epistemic account, the collective semantic account avoids the objections raised against its individualist counterpart in section 3 .

What about a collective noetic account, that is, an account on which scientific progress consists in increases in collective understanding? The feasibility of such an account hangs on at least two substantive issues about the nature of understanding that I cannot hope to settle here. Instead, I will raise the issues and briefly discuss the prospects for a collective noetic account in light of them. First, one might think that, unlike belief ${ }^{20}$ and knowledge, understanding has a phenomenal component ${ }^{21}$ that cannot be satisfied by collectives. ${ }^{22}$ It is perhaps for this reason that, despite the

knowledge. However, given similar arguments to those put forward in section 2, we can explain why the hermit's discoveries do not automatically contribute to scientific knowledge without denying that individual attitudes sometimes contribute to scientific knowledge. Ultimately, what seems to matter is the accessibility of information, not whether this information is recorded in some non-biological store. This more permissive approach, but not the more restrictive alternative Bird sometimes suggests, is consistent with the intuitive point that there could in principle be collective scientific knowledge among a community of inquirers with no written language.

${ }^{19}$ Bird (2020: 277-9) articulates an account of group belief that closely parallels his account of social knowledge.

${ }^{20}$ It is controversial whether belief has a phenomenal component. See, for instance, Cohen (1989: 368) for the view that belief that $p$ involves a disposition to feel that $p$ is true.

${ }^{21}$ Whether understanding has such a phenomenal component is controversial. Bourget (2017) provides a helpful overview of the controversy.

${ }^{22}$ The view that collectives cannot be the subjects of phenomenal states is widely, but perhaps not universally, held. Schwitzgebel (2015), for instance, argues that if materialism is true then some large collectives are probably conscious - although Schwitzgebel is himself unsure whether this is best understood as 
extensive and growing literature on group belief and group knowledge, there is yet very little work on group understanding. Boyd's (2019) recent argument for the existence of irreducible group understanding is a rare exception, and one that might well point the way forward for a collective noetic account. Notably, Boyd's argument for group understanding utilizes an account of understanding with no phenomenal component. Central to this account is the notion of grasping as a necessary condition on understanding, where grasping involves a set of abilities related to the proposition understood. ${ }^{23}$ As I noted in section 1, Dellsén deploys a similar approach to grasping in his development of the noetic account. Boyd argues that, in some cases where the relevant abilities are distributed across a group, that group is the subject of irreducibly collective understanding. Provided that some such non-phenomenal account of grasping is adequate - a claim I will not attempt to assess here - a collective noetic account of scientific progress remains viable.

The apparent possibility that scientific progress can be lost through the destruction of material stores of information presents a second possible concern for the collective noetic account. To address this concern, the proponent of a collective noetic account might insist that a collective's grasp may in principle be distributed across biological and non-biological components of the collective. Alternatively, the collective noetic account may perhaps be defended by appeal to a further condition on collective understanding that $p$ that is partially realized in material stores of information. An adequate consideration of either response would take us well beyond the main thesis of the present essay, and so I leave the issue here. For present purposes, the upshot of this brief discussion is that the development of a collective noetic account would require grappling with issues concerning how understanding is realized, and the sorts of entities that can possess it.

\section{Objections and replies}

I have argued that the most defensible PE accounts of scientific progress are collective $\mathrm{PE}$ accounts. In this brief section, I consider two objections to the case for the collective $\mathrm{PE}$ accounts developed above.

In a recent paper, Ross (2020) argues, consonant with what has been argued here, that science most plausibly progresses through epistemic improvements to communities, rather than individuals. However, Ross argues that PE accounts like those considered here fail to recognize that scientific progress occurs in intermediate stages of inquiry and, in particular, through the formulation of new questions, the collection of evidence, and through increased confidence in correct answers to questions. I now briefly argue that the relatively simple PE accounts discussed above are preferable to the richer accounts Ross defends.

First, there are problems with treating at least one of the individual interrogative attitudes Ross discusses as constitutive of progress. According to Ross, group wondering consists in formulation of a question and a commitment on the part of the group to investigate that question (2020: 13). Thus, on Ross's account, scientific progress might occur through the formulation by the scientific community of a question, and a commitment to determine the answer to that question. However, such an account has deeply counterintuitive consequences when combined with the plausible principle, suggested by Ross (2020: fn. 9), that if progress consists in the acquisition of some $x$,

support for the existence of phenomenally conscious groups or the falsity of materialism. See List (2018) for a recent critique of Schwitzgebel's line of argument.

${ }^{23}$ See also Hills (2015) for an account of understanding-why that takes such understanding to require similar abilities. 
then regress occurs when $x$ is lost. Suppose though that the scientific community wonders whether $p$. Now suppose the community comes to know that $p$. Presumably, the community will cease to wonder whether $p$. However, it hardly seems plausible that, even as some scientific progress is made, some is also lost through the community's ceasing to wonder - and more specifically ceasing to be committing to investigating - whether $p$. Another concern for Ross's approach is that, intuitively, a community undergoes just as much scientific progress if it increases its knowledge or understanding by chance discovery as if its epistemic improvements are precipitated by wondering. Otherwise, when comparing two communities that are alike in all respects except that the epistemic attitudes of only one were due to chance discovery, we would be forced to conclude, implausibly, that the other has progressed further.

There are more general problems with Ross's pluralistic approach. ${ }^{24}$ First, it is not clear that any amount of wondering, evidence collection, or increase in confidence amounts to scientific progress if it fails to culminate in the achievement of some PE state. For example, if Ross's approach were correct, then it would be possible in principle for a community to achieve substantial scientific progress by simply formulating a large number of research questions and committing to investigate these. Sufficient committed curiosity on the part of the group might in fact be sufficient for the community to achieve greater scientific progress than if it came to enjoy new knowledge or understanding. This, it seems, is implausible. So too is it implausible that fruitlessly collecting evidence is constitutive of scientific progress. ${ }^{25}$ It is somewhat more plausible that a community might achieve scientific progress by increasing its confidence in true scientific propositions, without necessarily ever arriving at full belief. However, this point might be accommodated by a version of the semantic approach treating credences, rather than binary beliefs, as central. On the whole, then, it is not clear that the proponents of $\mathrm{PE}$ accounts have reason to embrace a pluralistic approach to scientific progress that recognizes something beyond the development of PE attitudes as constitutive of scientific progress. Instead, the formation of interrogative attitudes like the ones Ross describes are best understood as facilitating scientific progress, rather than being constitutive of scientific progress itself.

A second objection threatens to render problematic the very idea of ascribing $\mathrm{PE}$ attitudes, especially knowledge, to communities, in cases in which the attitude in question is not possessed by any community member. ${ }^{26}$ Lackey (2014) alleges that accounts of social knowledge like Bird's $(2010,2014)$ - which allow for group knowledge to be partially realized in non-human components of collectives - conflict with the following plausible principle: ${ }^{27}$

\section{Knowledge-Action Principle (KAP)}

$\mathrm{S}$ knows that $\mathrm{p}$ only if $\mathrm{S}$ is epistemically rational to act as if p. (Lackey 2014: 287)

\footnotetext{
${ }^{24}$ Note that the objections raised here do not undermine all pluralist accounts - these objections are consistent with the development of collective knowledge and understanding both being constitutive of scientific progress, for instance.

${ }^{25}$ To bolster this claim notice that, as Ross acknowledges (2020: 5), collecting further evidence of a scientific fact does not amount to progress when that fact is already well-established. This indicates that the collection of evidence is not intrinsically progressive, but leads to progress just when it furthers the attainment of some attitude like true belief, knowledge, or understanding.

${ }^{26}$ Thanks to an anonymous referee for pressing me to consider this objection.

${ }^{27}$ Lackey (2014) raises a second objection against views that support such ascriptions. According to this objection, such views cannot provide an adequate account of group-level epistemic defeaters. However, this objection can be resolved by allowing that the mental states of human individuals can contribute to what a group knows. As I have suggested above (fn. 18), Bird's account of collective knowledge is most plausible when this possibility is allowed.
} 
Because groups can plausibly only act through their members, Lackey alleges that accounts that allow for groups to possess knowledge not possessed by members must either allow that groups can act in epistemically rational ways on propositions not known by members or must deny the KAP.

Lackey's objection to Bird's approach depends on an implausibly strong reading of the KAP, however. Knowing that $p$ does not guarantee the epistemic rationality of all the ways in which one might act as if $p$. To see this, consider the following case from Turri:

\section{Spiro}

Spiro is a spiteful guy who relishes causing people emotional pain. Out of spite, he plans to tell Lois that her fiancé just died. Some time before he embarks on executing his plan, he receives a text message from a reliable informant reporting that Lois's fiancé has indeed just died. So Spiro knows that the fiancé died. But this knowledge doesn't motivate him in the least to tell Lois that her fiancé died. He goes ahead and tells her out of pure spite. Intuitively this assertion is epistemically defective. (Turri 2011: 41)

Asserting that $p$ is a paradigmatic way of acting as if $p$. However, Spiro's knowledge plainly does not render his assertion epistemically rational - that knowledge is causally irrelevant to how Spiro acts. Similarly, suppose that the scientific community knows $q$ by way of some archived publication forgotten by every living member of the community. Then, suppose that the scientific community acts as if $q$ without first consulting this publication. Lackey is correct that such an action would be epistemically irrational on the part of the group. However, on a plausibly weakened version of the KAP, the scientific community's knowledge that $q$ does not secure the epistemic rationality of its action, and this is because that knowledge is causally irrelevant to the action. When the KAP is given a plausible reading - requiring that knowledge be causally implicated to rationalize action - it poses no threat to the attribution of knowledge not possessed by individual members to broader communities.

\section{Concluding remarks}

I have argued that the semantic, epistemic, and noetic accounts of scientific progress might well survive an apparent challenge from the social dimensions of scientific progress. To survive, however, such accounts must recognize collective epistemic subjects. There remains a question, raised here but not resolved, about what the relevant collective epistemic subjects are. ${ }^{28}$

\section{References}

Baird D. and Faust T. (1990). 'Scientific Instruments, Scientific Progress, and the Cyclotron.' British Journal for Philosophy of Science 41(2), 147-75.

Bird A. (2007). 'What is Scientific Progress?' Noûs 41(1), 64-89.

Bird A. (2008). 'Scientific Progress as Accumulation of Knowledge: A Reply to Rowbottom.' Studies in History and Philosophy of Science Part A 39(2), 279-81.

Bird A. (2010). 'Social Knowing: The Social Sense of 'Scientific Knowledge'.' Philosophical Perspectives 24(1), 23-56.

Bird A. (2014). 'When is There a Group that Knows? Distributed Cognition, Scientific Knowledge, and the Social Epistemic Subject.' In J. Lackey (ed.), Essays in Collective Epistemology, pp. 42-63. Oxford: Oxford University Press.

\footnotetext{
${ }^{28}$ I would like to extend my thanks to two anonymous referees for their extraordinarily thoughtful and productive comments on earlier drafts of this paper.
} 
Bird A. (2019). 'The Aim of Belief and the Aim of Science.' Theoria 34(2), 171-93.

Bird A. (2020). 'Group Belief and Knowledge.' In M. Fricker, P.J. Graham, D. Henderson and N.J. Pedersen (eds), The Routledge Handbook of Social Epistemology, pp. 274-83. New York, NY: Routledge.

BonJour L. and Sosa E. (2003). Epistemic Justification: Internalism vs. Externalism, Foundations vs. Virtues. Oxford: Wiley-Blackwell.

Bourget D. (2017). 'The Role of Consciousness in Grasping and Understanding.' Philosophy and Phenomenological Research 95(2), 285-318.

Boyd K. (2019). 'Group Understanding.' Synthese. doi: 10.1007/s11229-019-02492-3.

Clark A. (1997). Being There: Putting Brain, Body, and the World Together Again. Cambridge, MA: MIT Press.

Clark A. (2008). Supersizing the Mind: Embodiment, Action, and Cognitive Extension. Oxford: Oxford University Press.

Clark A. and Chalmers D. (1998). 'The Extended Mind.' Analysis 58(1), 7-19.

Cohen L.J. (1989). 'Belief and Acceptance.' Mind 98(391), 367-89.

Davies J. and Michaelian K. (2016). 'Identifying and Individuating Cognitive Systems: A Task-Based Distributed Cognition Alternative to Agent-Based Extended Cognition.' Cognitive Processing 17(3), 307-19.

De Ridder J. (2014). 'Epistemic Dependence and Collective Scientific Knowledge.' Synthese 191(1), 37-53.

Dellsén F. (2016). 'Scientific Progress: Knowledge versus Understanding.' Studies in History and Philosophy of Science Part A 56, 72-83.

Dellsén F. (2017). 'Understanding Without Justification or Belief.' Ratio 30(3), 239-54.

Dellsén F. (2018a). 'Scientific Progress: Four Accounts.' Philosophy Compass 13(11), e12525.

Dellsén F. (2018b). 'Scientific Progress, Understanding, and Knowledge: Reply to Park.' Journal for General Philosophy of Science 49(3), 451-549.

Douglas H. (2014). 'Pure Science and the Problem of Progress.' Studies in History and Philosophy of Science Part A 46, 55-63.

Gilbert M. (1987). 'Modelling Collective Belief.' Synthese 73(1), 185-204.

Gilbert M. (1989). On Social Facts. Princeton, NJ: Princeton University Press.

Gilbert M. (1994). 'Remarks on Collective Belief.' In F. Schmitt (ed.), Socializing Epistemology: The Social Dimensions of Knowledge, pp. 235-56. Lanham, MD: Rowman \& Littlefield.

Gilbert M. (2000). 'Collective Belief and Scientific Change.' In M. Gilbert (ed.), Sociality and Responsibility: New Essays in Plural Subject Theory, pp. 37-49. Lanham, MD: Rowman \& Littlefield.

Goldman A. (2014). 'Social Process Reliabilism: Solving Justification Problems in Collective Epistemology.' In J. Lackey (ed.), Essays in Collective Epistemology, pp. 11-41. Oxford: Oxford University Press.

Grimm S. (2006). 'Is Understanding a Species of Knowledge?' British Journal for the Philosophy of Science 57(3), 515-35.

Grimm S. (2011a). 'Understanding.' In S. Bernecker and D. Pritchard (eds), The Routledge Companion to Epistemology, pp. 84-94. London: Routledge.

Grimm S. (2011b). 'On Intellectualism in Epistemology.' Mind 120(479), 705-33.

Grimm S. (2015). 'Knowledge, Practical Interests, and Rising Tides.' In J. Greco and D. Henderson (eds), Epistemic Evaluation: Purposeful Epistemology, pp. 117-37. Oxford: Oxford University Press.

Hannon M. (2017). 'A Solution to Knowledge's Threshold Problem.' Philosophical Studies 174(3), 607-29.

Hannon M. (2020). 'Why Purists Should be Infallibilists.' Philosophical Studies 177(3), 689-704.

Harris K. (2019). 'Whose (Extended) Mind is it, Anyway?' Erkenntnis. doi: 10.1007/s10670-019-00172-9.

Harris K. (2020). 'Group Minds as Extended Minds.' Philosophical Explorations 23(3), 234-50.

Hawley K. (2003). 'Success and Knowledge-How.' American Philosophical Quarterly 40(1), 19-31.

Hetherington S. (2001). Good Knowledge, Bad Knowledge: On Two Dogmas of Epistemology. New York, NY: Oxford University Press.

Hetherington S. (2006). 'Knowledge's Boundary Problem.' Synthese 150(1), 41-56.

Hills A. (2015). 'Understanding Why.' Noûs 49(2), 661-88.

Hurley S. (2010). 'Varieties of Externalism.' In R. Menary (ed.), The Extended Mind, pp. 101-53. Cambridge, MA: MIT Press.

Hutchins E. (1995). Cognition in the Wild. Cambridge, MA: MIT Press.

Kuhn T.S. (1970). The Structure of Scientific Revolution, 2nd edition. Chicago, IL: University of Chicago Press.

Kuhn T.S. (1977). The Essential Tension. Selected Studies in Scientific Tradition and Change. Chicago, IL: University of Chicago Press. 
Kvanvig J. (2003). The Value of Knowledge and the Pursuit of Understanding. New York, NY: Cambridge University Press.

Lackey J. (2014). 'Socially Extended Knowledge.' Philosophical Issues 24(1), 282-98.

Lackey J. (2016). 'What is Justified Group Belief?' Philosophical Review 125(3), 341-96.

Laudan L. (1977). Progress and its Problems: Toward a Theory of Scientific Growth. Berkeley, CA: University of California Press.

Laudan L. (1981). 'A Problem-Solving Approach to Scientific Progress.' In I. Hacking (ed.), Scientific Revolutions, pp. 144-55. Oxford: Oxford University Press.

Lipton P. (2004). Inference to the Best Explanation, 2nd edition. London: Routledge.

List C. (2018). 'What is it Like to be a Group Agent?' Nô̂s 52(2), 295-319.

Milojevic M. (2020). 'Extended Mind, Functionalism and Personal Identity.' Synthese 197(5), 2143-70.

Mizrahi M. (2013). 'What is Scientific Progress? Lessons from Scientific Practice.' Journal for General Philosophy of Science 44(2), 375-90.

Niiniluoto I. (1984). Is Science Progressive? Dordrecht: D. Reidel.

Niiniluoto I. (1987). Truthlikeness. Dordrecht: D. Reidel.

Niinulouto I. (2014). 'Scientific Progress as Increasing Verisimilitude.' Studies in History and Philosophy of Science Part A 46, 73-7.

Niiniluoto I. (2017). 'Optimistic Realism About Scientific Progress.' Synthese 194(9), 3291-309.

Niiniluoto I. (2019). 'Scientific Progress.' In E. Zalta (ed.), Stanford Encyclopedia of Philosophy, http://plato. stanford.edu/archives/sum2011/entries/scientific-progress/.

Noë A. (2005). 'Against Intellectualism.' Analysis 65(4), 278-90.

Popper K.R. (1963). Conjectures and Refutations: The Growth of Scientific Knowledge. London: Hutchinson.

Popper K.R. (1972). Objective Knowledge, Revised edition. Oxford: Clarendon Press.

Ross L.D. (2020). 'How Intellectual Communities Progress.' Episteme. doi: 10.1017/epi.2020.2.

Rowbottom D. (2010). 'What Scientific Progress is Not: Against Bird's Epistemic View.' International Studies in the Philosophy of Science 24(3), 241-55.

Rowbottom D. (2015). 'Scientific Progress Without Increasing Verisimilitude: In Response to Niiniluoto.' Studies in History and Philosophy of Science Part A 51, 100-4.

Schwitzgebel E. (2015). 'If Materialism is True, the United States is Probably Conscious.' Philosophical Studies 172(7), 1697-721.

Stanley J. and Williamson T. (2001). 'Knowing How.' Journal of Philosophy 98(8), 411-44.

Turri J. (2011). 'The Express Knowledge Account of Assertion.' Australasian Journal of Philosophy 89(1), $37-45$.

Wray K.B. (2001). 'Collective Belief and Acceptance.' Synthese 129(3), 319-33.

Zagzebski L. (2001). 'Recovering Understanding.' In M. Steup (ed.), Knowledge, Truth, and Duty: Essays on Epistemic Justification, Responsibility, and Virtue, pp. 235-52. New York, NY: Oxford University Press.

Keith Raymond Harris is a Visiting Assistant Professor of Philosophy at the University of Iowa. His research concerns a range of issues in social and individual epistemology, social metaphysics, and cognitive science.

Cite this article: Harris KR (2021). Scientific Progress and Collective Attitudes. Episteme 1-20. https:// doi.org/10.1017/epi.2021.6 